DOE/RL-97-52

\title{
Basic Planning and Work Performance of Hanford Site \\ Environmental Management Activities
}

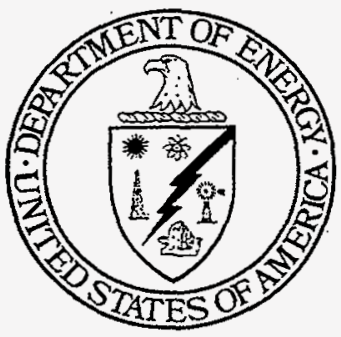

Department of Energy

Richland Operations Office

June 1997 


\section{RELEASE AUTHORIZATION}

Document Number: $\quad$ DOE/RL-97-52, Revision 0

Document Title:

Basic Planning and Kork Performance of Hanford Site Environmental Management Activities

This document, reviewed in accordance with DOE Order 1430.1D, "Scientific and Technical Information Management," and DOE G 1430.1D-1, "Guide to the Management of Scientific and Technical information," does not contain classified or sensitive unclassified information and is:

APPROVED FOR PUBLIC RELEASE



v. L. Birkiand

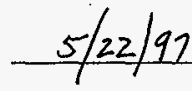

Lockheed Martin Services, Inc. Document Control/Information Clearance

Rovowod for Apphed Technology, Businoss Sonstive, Classified, Copyrighted, Export Controlled, Patent, Personal/Private, Prophetary, Frotectod CRADA, Trademark, Unclassified Controllod Nuclear Infomation.

Trademark Disclaimer. Reforence heroin to any specifie commercial product, process, or service by trade narme, trademark. manufacturer, or otherwise, does not necessiarily constitute or imply its ondorsement, recommandation, or favoring by the United States Govemmont or any agency thereof or ite contractore or subcontractors. The viowe and opinions of authors expressed herein do not nocessarily. state or reflect those of the United States Govomment or ony agency thoreof. This roport has been roproduced from the best avoilable copy.

Printed in the United States of Americe.

Availabie to the U.S. Department of Energy and its controctors from the U.S. Department of Eneray Office of Scientific and Technical Information, P.O. Box 62, Oak Ridge, TN 37831: Tolophone: 423/576-8401.

Available to the public from the U.S. Department of Commerce National Tochnical Information Service, 5285 Port Royal Road. Spring field, VA 22161; Telephone: 703/487-4650. 


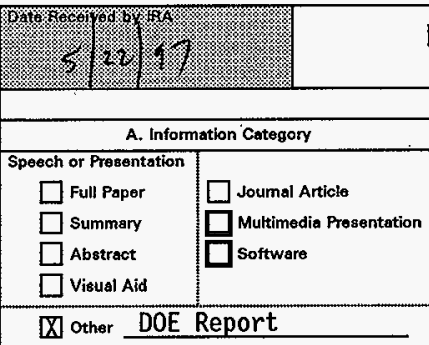

\section{INFORMATION RELEASE REQUEST - (Long Form)}

(GRAY SHADED AREAS NOT TO BE FILLED IN BY INITIATOR]

\section{COMPLETE THIS SECTION FOR ALL DOCUMENTS}

B. Documant ID Number (inctude rev., vol., ote.)

DOE/RL-97-52, Rev, 0

C. List attachmonts (i.e., copyright permission, copyright transfer)

DOE/RL Document Clearance Form signed by DOE/RL authorities

\section{Document Title}

Basic Planning and. Work Performance of Hanford Site Environmental Management DOE/RL Activities




D0E/RL-97-52, Rev. 0 Document ID Number

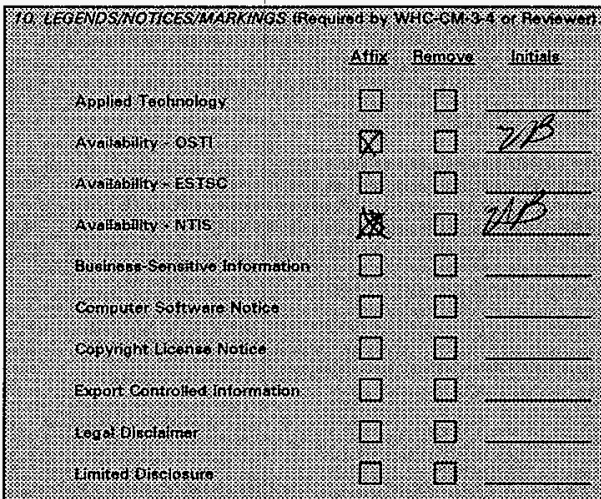

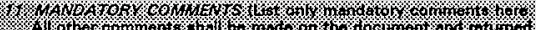

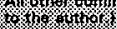

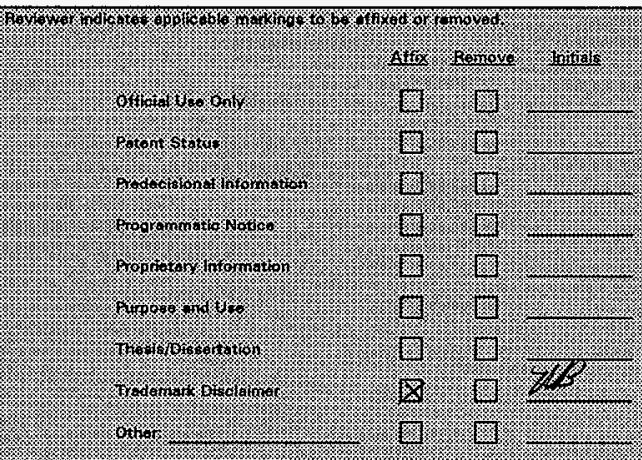

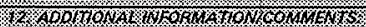

(t)

\section{Date}



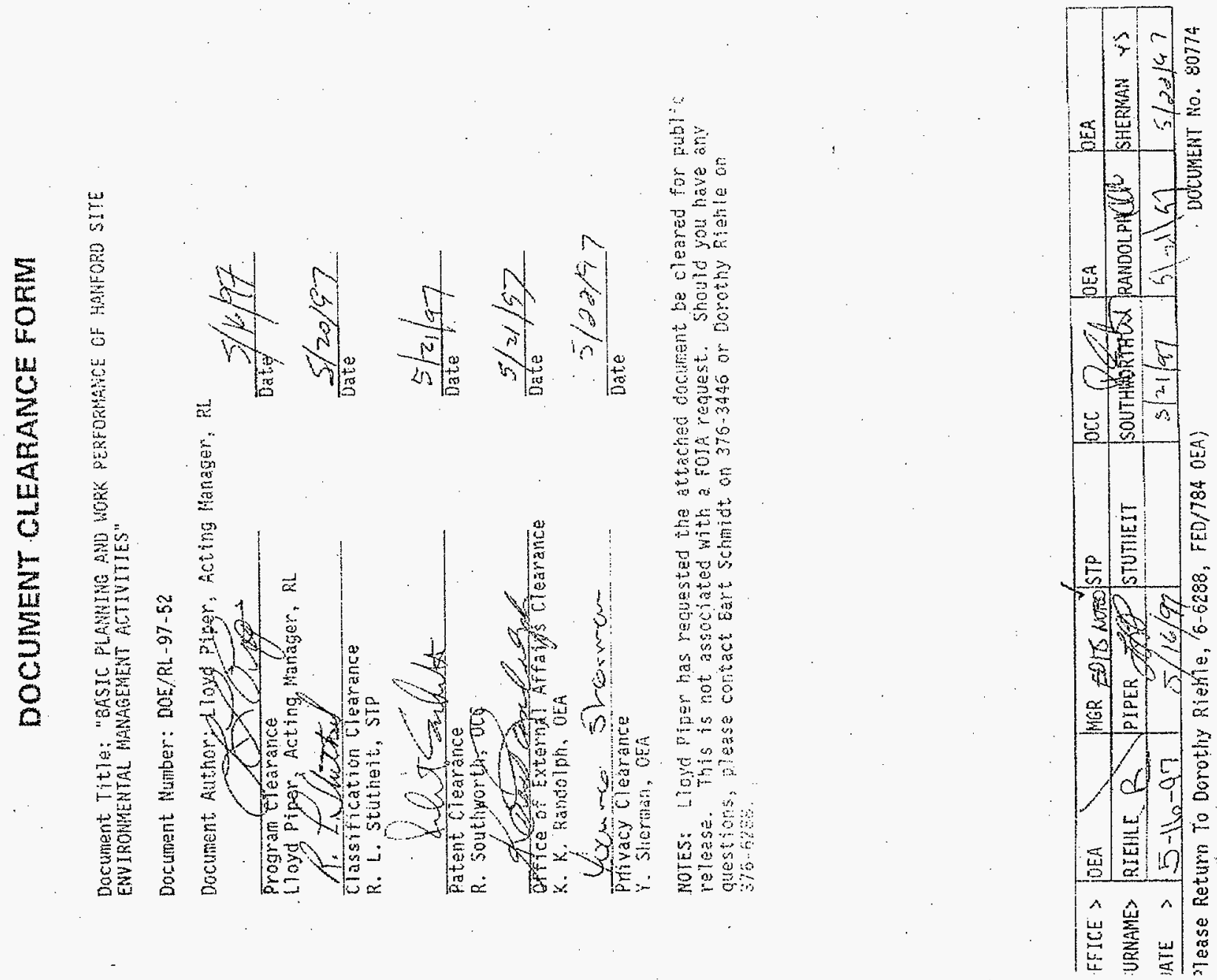
DOE/RL-97-52

Basic Planning and Work Performance of Hanford Site

Environmental Management Activities

June 1997

Department of Energy

Richland Operations Office 


\section{Table of Contents}

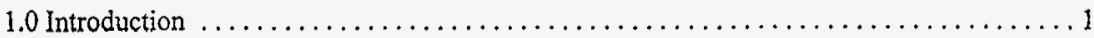

2.0 Baseline Management and Planning Activities $\ldots \ldots \ldots \ldots \ldots \ldots \ldots \ldots \ldots \ldots \ldots \ldots$

3.0 Relationship of Planning and Formal Decision Making $\ldots \ldots \ldots \ldots \ldots \ldots \ldots \ldots \ldots \ldots \ldots \ldots$

3.1 . Tribal, Regulatory, and Public Involvement in Decision Making $\ldots \ldots \ldots \ldots 2$

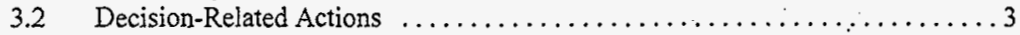

3.3 NEPA and CERCLA Considerations $\ldots \ldots \ldots \ldots \ldots \ldots \ldots \ldots \ldots \ldots, \ldots \ldots$



3.5 Hanford Site Environmental Management Specification ..............

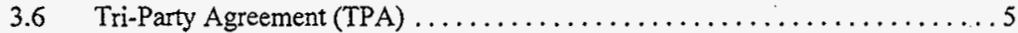

3.7 Relationship of Decision Making and Advisory Groups .............. 6

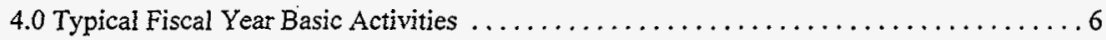

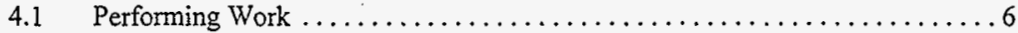

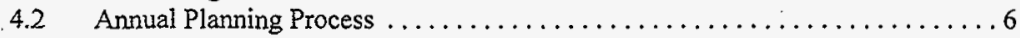

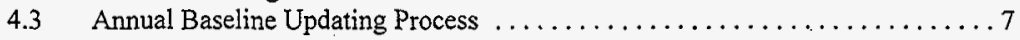

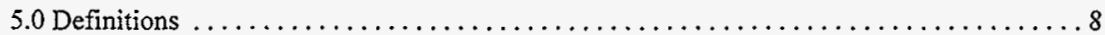

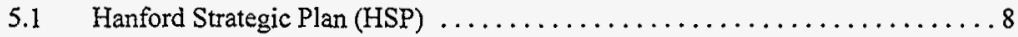

5.3 Baseline Updating Guidance (BUG) $\ldots \ldots \ldots \ldots \ldots \ldots \ldots \ldots \ldots, \ldots, 8$

5.4 Site Environmental Management Specification ..................

5.5. Environmental Management Project Specification ................. 9

5.6 Project Baselines/Multi-Year Work Plans (MYWPs) . . . . . . . . . . . . 9

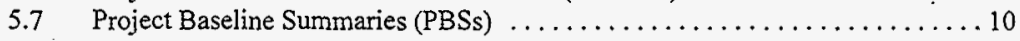

5.8 Service/Indirect Baselines - Annual Work Plans (AWPs) $\ldots \ldots \ldots \ldots \ldots 10$

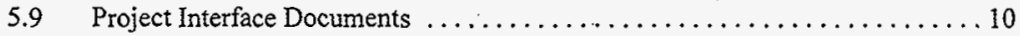





5.12 Hanford Site Accelerating Cleanup: Focus on 2006 (2006 Plan) and Updates . . 12

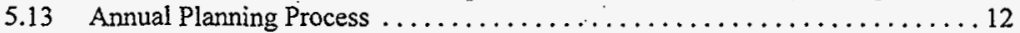

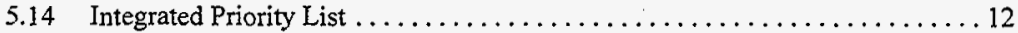

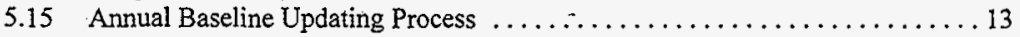

5.16 Baseline/Site \& Project Specification Change Control Process $\ldots \ldots \ldots \ldots \ldots 13$

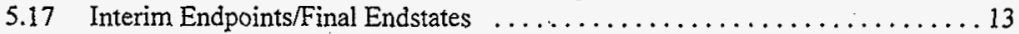

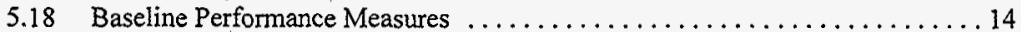

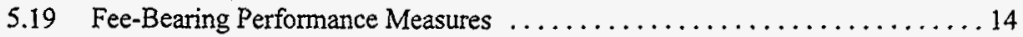

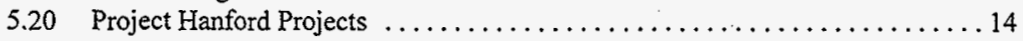




\subsection{Introduction}

This document provides an overview of the basic planning and work of the Department of Energy Richland Operations Office (DOE-RL). It defines key terms, concepts, and processes used in Hanford's Environmental Management (EM) activities. It is not intended to provide complete details on the topics discussed. It does, however, provide a roadmap of the overall process so that opportunities for tribal, regulator, and public involvement can be clearly identified.

Many documents are referenced in this plan. Each is described in some detail in Section 5 , and cross-references to that section are provided throughout the discussion in Sections 1 through 4.

\subsection{Baseline Management and Planning Activities}

DOE-RL authorizes, manages, and performs Hanford environmental management work to a baseline that reflects the technical requirements, estimated cost, and estimated schedule. The baseline is developed as a work plan for project activities to accomplish the desired results of the Site Environmental Management Specification (see Section 5.4). Multi-Year Work Plans (MYWPs) (see Section 5.6) and Annual Work Plans (AWPs) (see Section 5.8) are the expression of the baseline and serve as a performance measurement gauge. In summary, the baseline is what DOE-RL and its contractors work to achieve. It is a formal cocument and is updated through a change control process.

At the same time cleanup work is being performed to meet the current baseline, activities such as "blue sky" thinking, planning, budgeting, and formal decision processes are going on to consider potential changes to the baseline. The predecisional development of planning alternatives and the analysis of these alternatives are part of a formative stage where there is significant interest in tribal, regulatory, and public involvement. At this stage in the planning and decision process, the baseline does not reflect the predecisional thinking or alternatives. Only after a decision is made to change the baseline and the change process is completed will the revised baseline reflect the outcome of a decision made through planning activities. Figure 1, Baseline Management and Planning Activities (also known as the "cloud diagram"), depicts these simultaneous activities. 


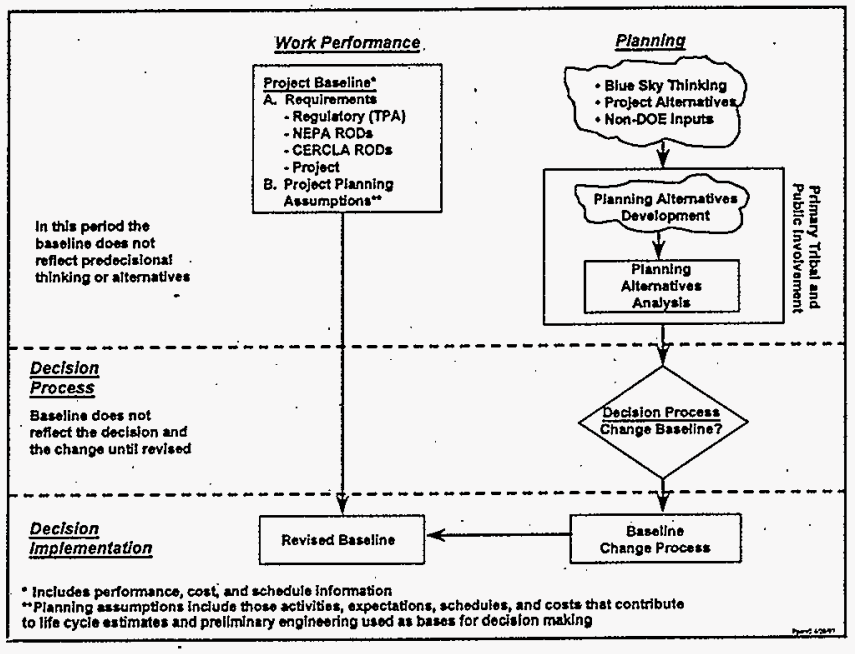

Figure 1. Baseline Management and Planning Activities

\subsection{Relationship of Planning and Formal Decision Making}

Planning efforts result in changes to the baseline through established formal decision processes. This section summarizes the relationship of DOE-RL's planning efforts to formal decision making.

\subsection{Tribal, Regulatory, and Public Involvement in Decision Making}

DOE-RL has been moving toward earlier and earlier tribal, public, and regulator involvement in its planning and decision making so that it can share information and receive valuable input and recommendations during the formative stages of these processes. DOE-RL has been releasing very early drafts of planning guidance and predecisional analysis, quite often before this material has been reviewed by DOE 
management. The material may therefore be incomplete and possibly inconsistent with other documents and may not reflect DOE's final position. At this time, DOE believes that it is preferable to have such open involvement in the DOE planning process. Those who receive such early draft documents should recognize that they are by nature incomplete, unreviewed to a large extent, and potentially contradictory.

\subsection{Decision-Related Actions}

In general terms, decision-related actions by DOE-RL should be viewed in three major stages: as parts of the planning process, the decision process, and decision implementation.

The planning process involves such areas for activities and documentation as

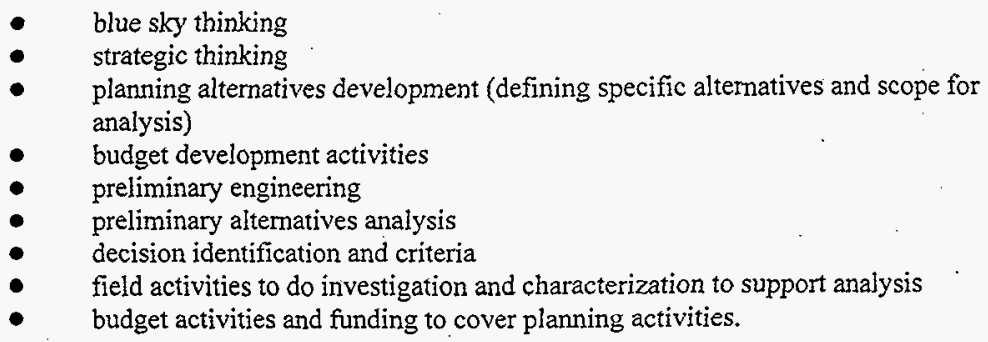

The decision process involves such activities as

- analysis of the results from the planning process

- formal decisions through National Environmental Policy Act (NEPA), Comprehensive Environmental Response Compensation and Liability Act (CERCLA), and Resource Conservation and Recovery Act (RCRA) processes'

- baseline/site and project specification changes that do not require formal NEPA or CERCLA Records of Decision (RODs)

- budget allocations that support implementation of decisions after they are finalized. 


\section{Decision implementation involves}

- final engineering

- field activities to carry out the decision.

\subsection{NEPA and CERCLA Considerations}

In general, NEPA regulations prohibit DOE from taking any major federal action that would have an adverse environmental impact or prejudice the final decision in a NEPA ROD before the ROD is approved. The CERCLA process, as followed by DOE, includes consideration of NEPA values so that a CERCLA ROD is sufficient authority to implement a decision without a parallel NEPA process and NEPA ROD. The NEPA and CERCLA requirements allow the "planning process" as described above to be performed prior to entering a formal decision process.

\subsection{DOE-RL Planning Documents}

The DOE Hanford Strategic Plan (HSP) (see Section 5.1), the Mission Planning Guidance (MPG) (see Section 5.2), the Baseline Updating Guidance (BUG) (see Section 5.3), and the Hanford Site Accelerating Cleanup: Focus on 2006 (2006 Plan) (see Section 5.12) all provide guidance and direction for planning and analysis that is not yet covered by NEPA or CERCLA documents. These represent planning process work and, as such, do not need advance NEPA decisions, but instead show where NEPA/CERCLA decision processes will be needed. The resultant NEPA/CERCLA RODs and Tri-Party Agreement (TPA) commitments take precedence over, and will cause changes and adjustments to be made to, the HSP, MPG, BUG, 2006 Plan, or other planning process documents as necessary.

\subsection{Hanford Site Environmental Management Specification}

The Hanford Site Environmental Management Specification (see Section 5.4) is the fundamental work definition document for cleanup, infrastructure, and environmental management work at Hanford. Through the application of systems engineering to the many requirements and planning documents and processes, this specification captures the applicable requirements and planning assumptions for sitewide activities and the individual project-specific activities. The requirements and planning assumptions reflect DOE-RL's application of the values, priorities, and critical success factors expressed by those involved with and affected by Project Hanford.

The prime contractors develop project baselines and work plans to implement this specification. See Figure 2, Basic Site Documents. 


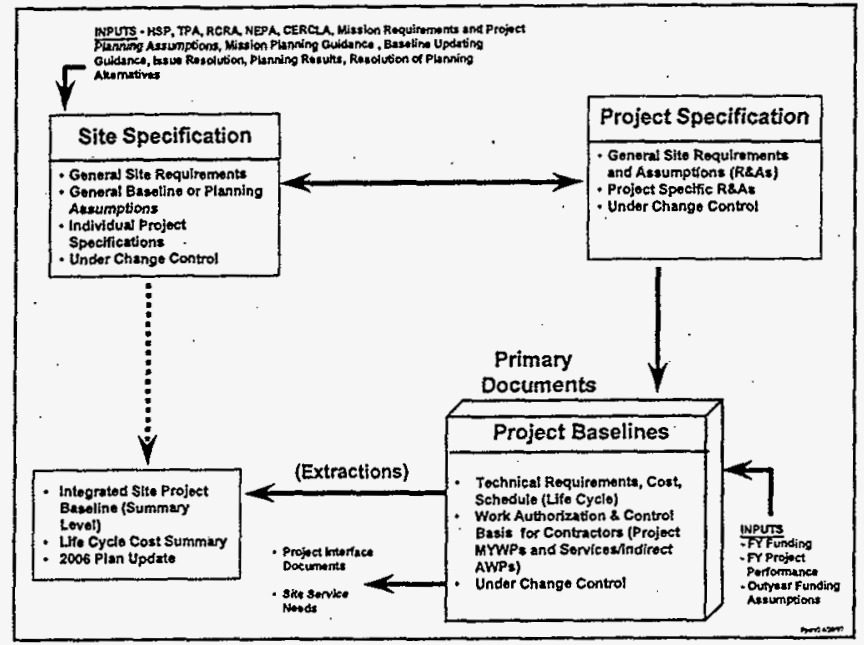

Figure 2. Basic Site Documents

\subsection{Tri-Party Agreement (TPA)}

The Tri-Party Agreement (TPA) is the primary compliance agreement governing the environmental management cleanup of the Hanford Site. The three signatories are the United States Environmental Protection Agency (EPA), the Washington Department of Ecology (WDOE), and DOE-RL. The TPA contains the formal commitments of DOE for environmental cleanup that are legally enforceable and could subject $D O E-R L$ to fines and penalties if they are not met. The TPA also contains processes for administering, expanding, modifying, and resolving disputes among the parties. Additionally, the TPA is the source of many of the specific requirements in the Site Environmental Management Specification (see Section 5.4). 


\subsection{Relationship of Decision Making and Advisory Groups}

The definitions in Section 5 of this document indicate broad responsibilities for who performs and approves the work associated with the overview presented. Numerous "committees," such as the DOE-RI Site Management Board (SMB), have a major role to play in primary decisions in the basic contractor processes described. Numerous other "committees," such as the Site Technology Coordination Group (STCG), have a key role to play in decisions or recommendations in specialized areas. These decisions or recommendations serve as significant input or as a basis for a decision in the basic contractor processes described in the overview. It is beyond the intent of this overview to. describe the roles of all such "committees" in the planning and decision process.

\subsection{Typical Fiscal Year Basic Activities}

\subsection{Performing Work}

Work is performed by the Hanford contractors in accordance with the baseline work plans that implement the Site Environmental Management Specification. For projects these are the Multi-Year Work Plans (MYWPs) (see Section 5.6). For services and indirect work activities these are Annual Work Plans (AWPs) (see Section 5.8).

\subsection{Annual Planning Process}

This process occurs in the first part of the fiscal year (FY) and involves

- a review of the Hanford Strategic Plan (HSP)

- development of Mission Planning Guidance (MPG) to guide contractor planning activities

- preparation of the budget submittal for the fiscal year two years in the future $(F Y+2)$. This is a primary time for tribal and public involvement. The FY+2 budget submittal to DOE Headquarters (HQ) will typically contain three elements: - Project Baseline Summaries (PBSs) (see Section 5.7)

- an Integrated Priority List (IPL) for the Site (see Section 5.14)

- a 2006 Plan update.

The current FY baseline will be updated to reflect any required changes developed in the Annual Planning Process (see Section 5.13).

Future FY potential changes to the baselines will not be incorporated until the Annual Baseline Updating Process at year end (see Section 5.15). 


\subsection{Annual Baseline Updating Process}

This process occurs after the results of the FY+2 budget resolution by DOE-HQ are known and involves development of the Baseline Updating Guidance (BUG) to guide contractor development of any revised baselines and work plans necessary. for the next fiscal year (FY+1). If there are no major funding shifts for the upcoming years, and no major DOE directed changes in the project technical approach or schedule for a project, then changes to the baseline should be minimal. The conclusion of this process results in the approved work plans and work authorizations for the next fiscal year and revised baselines as necessary. This is a primary time for tribal and public involvement.

In the next fiscal year, the basic activities repeat, starting with those in Section 4.1. See Figure 3, Typical Fiscal Year (FY) Calendar.

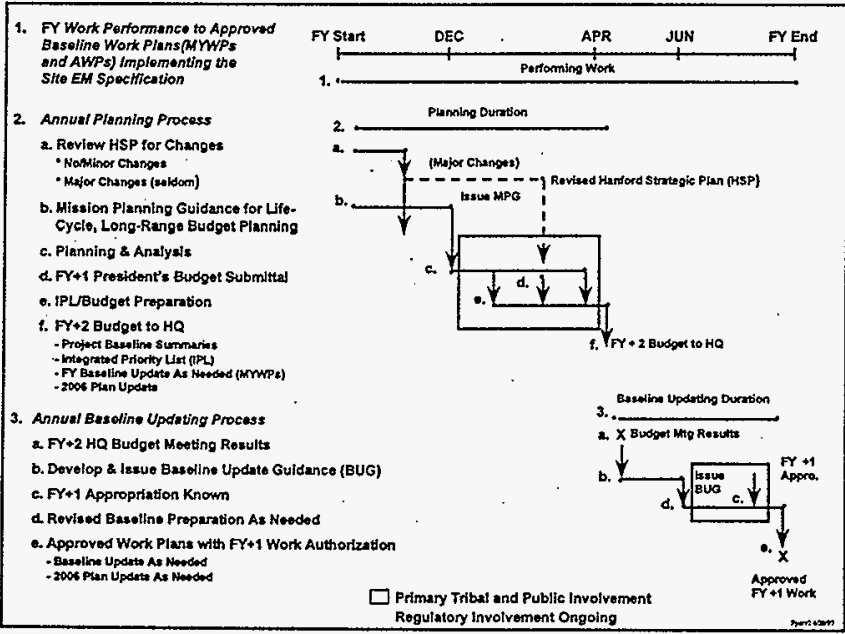

Figure 3. Typical Fiscal Year (FY) Calendar 


\subsection{Definitions}

The following definitions clarify the responsibility, purpose, content, and schedule for each of the major plans, processes, and concepts that comprise DOE-RL's Basic Planning and Work Performance.

\subsection{Hanford Strategic Plan (HSP)}

Generator: DOE-RL

Purpose: Establishes the strategic planning direction for the Hanford Site.

Contents: Identifies the vision, missions, values, goals, strategies, critical success factors and key success indicators. A planning document that reflects decisions and planning assumptions that will lead to additional decision making.

Schedule: Updated in the Annual Planning Process as determined by RL Site Management Board.

\subsection{Mission Planning Guidance (MPG)}

Generator: DOE-RL [Planning and Integration Division (PID) coordinates RL input] Purpose: A planning document for the Annual Planning Process to provide guidance for changes or potential changes to the contractor or project specifications, or baseline issued to the PHMC and other RI prime contractors. Initiates development of the Hanford budget submission for the fiscal year (FY) two years in the future $(F Y+2)$ to DOE-HQ.

Contents: Provides potential specification or baseline changes, a basis for prioritization of work, budget targets, and schedule targets if changed.

Schedule: Issued annually in mid-December in the Annual Planning Process and not updated.

\subsection{Baseline Updating Guidance (BUG)}

Generator: DOE-RL (PID coordinates RL input)

Purpose: . A planning document for the Annual Baseline Updating Process to provide updated guidance to the PHMC and other RI prime contractors that guide changes to the contractor specification or baseline with particular focus on the next fiscal year $(F Y+1)$.

Contents: Changes to the contractor/project specifications, baselines, alternatives for analysis, updated Budget Targets; updated schedule and mission-level performance objectives and measures. 
Schedule: Issued annually in mid-June in the Annual Baseline Updating Process and is not revised. The approved revisions to the contractor/project specifications, project baselines, and work plans constitute the implementation of the BUG through the updating process and govern work execution in the next fiscal year.

\subsection{Site Environmental Management Specification}

Generator: PHMC with input from other prime contractors and DOE. Approved by DOE-RL.

Purpose: $\quad$ Provides execution direction to the PHMC and other RL prime contractors. Applicable to the cleanup, infrastructure, and environmental management mission.

Contents: General introduction to Hanford Site Environmental Management mission with a compilation of the General Site Environmental Management Requirements and Planning Assumptions with a separate listing of the project specific requirements and planning assumptions (i.e., Project Specifications) for each of the Project Hanford projects. In general the requirements and planning assumptions are performance and results based.

Schedule: A current document under change control.

\subsection{Environmental Management Project Specification}

Generator: Prime contractors with-DOE-RL guidance and approval.

Purpose: $\quad$ Provides execution direction to the $\mathrm{PHMC}$ and other $\mathrm{Rl}$ prime contractors, applicable to the cleanup, infrastructure, and environmental management mission for a project.

Contents: A listing of the project specific requirements and planning assumptions for each of the Project Hanford projects. In general the requirements and planning assumptions are performance and results based.

Schedule: A current document under change control.

Note: The "Project Specification" will be the first part of the MYWP or the AWP supporting the detailed work plan and life-cycle plan to achieve the specification.

\subsection{Project Baselines/Multi-Year Work Plans (MYWPs)}

Generator: Contractors with DOE-RL guidance and approval.

Purpose: $\quad$ Planning, basis of authorizing and executing work at the project level. MYWPs are the expression of the project baseline. The MYWPS demonstrate the contractor's plan for meeting the project specification. Baselines reflect expected performance.

Contents: Detailed, project level estimated cost, schedule, scope, and performance measures and expectations for the entire project life cycle. 
Schedule: A current document under change control. In the Annual Baseline Updating Process changes are submitted to the DOE-RL project manager for review in August (draft) and in September for RL approval.

\subsection{Project Baseline Summaries (PBSs)}

Generator: Contractors with DOE-RL guidance and approval.

Purpose: A summary level document for projects. The associated MYWP contains a greater amount of detail. The PBS contains baseline information, risk information, and baseline performance measures. During the Annual Planning Process, additional planning information on budget scenarios is included for budget submittals.

Contents: Specific contents are determined by DOE Headquarters.

Schedule: Actively utilized during the Annual Planning Process. Baseline information updated from the MYWPs as necessary with budget information updated at various points in the Budget Process.

\subsection{Service/Indirect Baselines - Annual Work Plans (AWPs)}

Generator: Contractors with DOE-RL guidance and approval.

Purpose: Planning, basis of authorizing and executing support activities to operate the Hanford Site and provide support to Hanford projects. The AWPs are the expression of the baseline for projects and indirect activities that do not have a full life-cycle MYWP. Baselines reflect expected performance.

Contents: Similar to MYWPs including life-cycle elements as appropriate for facilities and capabilities planning and acquisition.

Schedule: A current document under change control. In the Annual Baseline Updating Process submitted to DOE-RL for review in August (draft) and in September for RL approval.

\subsection{Project Interface Documents}

Generator: PHMC, input provided by other prime contractors,

Purpose: Describe and quantify current and future interfaces of each project's external activities so that appropriate sitewide integration can occur.

Contents: List of inter-project interfaces with current and future needs.

Schedule: A current set of documents under change control. In the Annual Baseline Updating Process submitted in August (draft) and September (final) to DOE-RL for information. 
5.10 Integrated Site Baseline (ISB)

Generator: PHMC, input provided by other prime contractors. Approved by DOERL.

Purpose: Integrated life-cycle cost, schedule, and technical baseline for the Project Hanford Environmental Management projects, that demonstrates appropriate interaction and sequencing of the individual project activities to accomplish the desired outcomes of the Site Environmental Management Specification.

Contents: Summary level major technical, cost, and schedule baseline extracted from the project baselines.

Schedule: In FY97, July 31; thereafter a current document under change control.

\subsection{Stretch and Breakthrough Goals}

Generator: Contractors with DOE-RL guidance and approval.

Purpose: Goals for performance that are better, faster, at lower cost than the expected performance in the baseline that are part of the 2006 Plan vision.

Contents: Stretch Goal - This category refers to intended schedule and/or cost efficiencies that accomplish the same scope sooner or for less money (e.g., accelerate deactivation of PUREX by four months). Stretch goals don't necessarily require any additional resources or external formal decisions to implement.

Breakthroughs - 1) Refers to "outrageous" goals of massive efficiency gains that far exceed stretch goals where you believe the goal may be achievable, but no clear plan or path has yet been established. Once a plan or path has been defined (or becomes apparent), this may become a stretch goal, or even part of the baseline. 2) Refers to improvements in cost and/or schedule which may change the scope/endpoints/safety objectives for the project (and potentially require changes in regulations, contracting, etc). 3) Refers to improvements in cost, schedule and/or activity which may require explicit investment decisions to implement.

Schedule: As developed and approved. 


\subsection{Hanford Site Accelerating Cleanup: Focus on 2006 (2006 Plan) and Updates}

Generator: PHMC, input provided by the other prime contractors. Approved by DOERL.

Purpose: The Hanford Site Accelerating Cleanup: Focus on 2006 is a vision for 2006 that contains the baseline and, in addition, stretch/breakthrough goals. A planning document to focus resources of DOE-RL on expediting cleanup activities to achieve major progress at Hanford by 2006.

Contents: Subset of scope and schedule plans and goals extractable from the project baselines and identified with 2006 Plan.

Schedule: Tentatively update status of progress toward 2006 Plan goals biannually in March and September.

\subsection{Annual Planning Process}

Generator: Contractors with guidance and decisions by DOE-RL.

Purpose: Review and redefine the project plans as necessary to accommodate Hanford's annual federal budget development, authorization, and appropriation process. A primary time for tribal and public involvement.

Contents: Project plans are integrated and documented in Project Baseline Summaries (PBSs). PBSs are summarized into Site Plans and the various Site Plans are prioritized and summarized into the National Plan. The National Plan is used by HQ to manage the DOE complex and to develop the DOE budget requests to the Office of Management and Budget (OMB) for the President's budget submittal to Congress. Plans are traceable to project details.

Schedule: $\quad$ See Typical Fiscal Year Calendar, Figure 3.

\subsection{Integrated Priority List (IPL)}

Generator: PHMC with input from other prime contractors, guidance and approval from DOE-RL.

Purpose: Provide a list of contractor work elements (both by program and sitewide) in terms of priorities that have been established using a set of RL-approved decision criteria, e.g., health and safety, risk, mortgage reduction, etc. The list guides the funding and scheduling of work in a budget-constrained environment. Reflects Mission Planning Guidance.

Contents: Identification of work scope in priority order; priority-setting decision criteria; costs associated with each work element; critical relationships between work elements to group work elements noted into priority categories.

Schedule: Refine during the Annual Planning Process for the resultant budget submittal to DOE Headquarters. 


\subsection{Annual Baseline Updating Process}

Generator: Contractors with guidance and approval by DOE-RL.

Purpose: Annually and formally revise the project plans and Project Baseline

Summaries to refiect current progress and priorities, DOE-HQ appropriations allocations to sites, and site allocations to projects. A primary time for tribal and public involvement.

Contents: Updating will use the approved Baseline/Site \& Project Specification Change Control Process (Section 5.16). Without significant changes in funding or approach, the updating should be minimal.

Schedule: See Typical Fiscal Year Calendar, Figure 3.

\subsection{Baseline/Site \& Project Specification Change Control Process}

Generator: DOE-RL, contractors.

Purpose: To control changes to the cost, schedule, and technical baselines such that contractor and project objectives as manifested in those baselines are always reviewed and approved by the appropriate authority levels.

Contents: Change packages that describe proposed changes to contractor and project specifications and/or baselines including rationale for, impacts, and timing of those changes. Process is characterized by approved procedures, change approval authority at appropriate levels, communication of approved changes to affected organizations, and planning and tracking of change implementation.

Schedule: Real time as needed changes are identified.

\subsection{Interim Endpoints/Final Endstates}

Generator: DOE-RL with input from DOE-HQ, contractors, and tribal, regulatory, and public involvement.

Purpose: Final endstates represent the conditions present at the conclusion of Project Hanford. Interim endpoints are project objectives that do not necessarily reflect final project endstates at the conclusion of project Hanford. Interim endpoints represent a partial completion to a known endstate or an interim state for concluding project activities pending a decision on a final endstate. These identify final targets for cleanup and interim milestones needed to define progress.

Contents: Specific to the area, material, or project.

Schedule: Maintained in a current state in the Project Specification as a requirement or a planning assumption. 


\subsection{Baseline Performance Measures}

Generator: DOE-RL with input from DOE-HQ, contractors.

Purpose: Judge progress toward baseline performance on projects, ES\&H, and indirect/support activities.

Contents: Performance objectives and measures related to Hanford projects.

Schedule: Ongoing, revised as necessary, typically during the Annual Baseline Updating Process.

\subsection{Fee-Bearing Performance Measures}

Generator: DOE-RI Fee Administration Board (FAB) for the PHMC.

Purpose: Incentivize contractors to achieve identified objectives and expectations consistent with timely, economical progress toward cleanup endpoints or endistates.

Contents: Specific, detailed performance measures (objectives and measures) related to the cleanup, infrastructure, and environmental management mission which have fee potential for the contractors.

Schedule: Mid-September.

\subsection{Project Hanford Projects}

Generator: DOE-RL or prime contractors, approved by DOE-RL.

See Figure 4, FY 1997 EM Project Hanford Breakdown Structure (in the 2006 Plan). 
(*indicates projects for which project specifications are not required.)

1. Tank Waste Remediation System Project

Tank Waste Characterization Project

Tank Safety Issue Resolution Project

Tank Farms Operations Project

Retrieval Project

Process Waste Support Project

Privatization Phase I

Privatization Phase II

Privatization Infrastructure

Immobilized Tank Waste Storage and Disposal Project

*TWRS Management Support

2. Waste Management Project

Spent Nuclear Fuels Project

Canister Storage Building OPS

Solid Waste

Solid Waste Storage and Disposal

Liquid Waste Program

Analytical Services

Waste Minimization (HQ 7332)

3. Facility Transition Project

B Plant Sub-Project

WESF Sub-Project

PUREX Sub-Project

300 Area/SNM Sub-Project

PFP Deactivation

PFP Stabilization

PFP Vault Management

324/327 Facility Transition Project

$\mathrm{K}$ Basin Deactivation

Accelerated Deactivation Project

Advance Reactors Transition

*Transition Project Management

Landlord

Hanford Surplus Facility Program 300 Area Revitalization Project

Figure 4. FY 1997 EM Project Hanford Breakdown Structure 
4. Environmental Restoration Project

100 Area Source Remedial Action

200 Area Source Remedial Action

300 Area Source Remedial Action

Environmental Restoration Disposal Facility Project

Surveillance and Maintenance

Decontamination and Decommissioning

Long Term Surveillance and Maintenance

Ground Water Management Project

N Pilot Project.

*ER Program Management and Support

5. Science \& Technology Project

*PNNL Waste Management Project

Tanks Focus Area

Mixed Waste Focus Area

Subsurface contaminates Focus Area

D\&D Focus Area

Characterization Technologies

Efficient Separations

Robotics Technology

EM Science Program

6. HAMMER

7. *Mission Support

*Transportation \& Packaging Services

*Richland Analytical Services

*RL Directed Support

Figure 4. (Contd) 